\title{
REFLEXÃO A RESPEITO DO PROBLEMA DA REFERÊNCIA A TERMOS FICCIONAIS EM PERPECTIVAS DA FILOSOFIA ANALÍTICA E EPISTEMOLOGIA
}

Approaches upon the problem of reference to fictional terms in the perspectives of analytical philosophy and epistemology

Ana Catarina Souza Araújo ${ }^{1}$

RESUMO: O presente artigo intitula-se: Reflexão a respeito do problema da referência a termos ficcionais em perspectivas da filosofia analítica e epistemologia. O objetivo principal do trabalho consiste em analisar como o problema da referência a termos ficcionais influência na relação entre linguagem e realidade partindo da visão da filosofia analítica e epistemologia em especial na visão de Wittgenstein em suas produções dos anos 1929 e 1930. Busca-se caracterizar na filosofia de Wittgenstein como as soluções epistêmicas tradicionais não fecham as lacunas que se forma em relação aos problemas do discurso falso, a referência a termos ficcionais. O projeto tomará por base as seguintes obras da literatura de filosofia analítica: de Frege, em especial Sentido e referência; de Russell, principalmente o Da denotação; e das obras de Ludwig Wittgenstein tomaremos principalmente as produções pós-Tractatus, mas também obras como Notebooks e o próprio Tratactuslogico-Philosophicus enquanto fios condutores de seus pensamentos mais básicos, e em suas obras pós-Tractatus o foco estará no livro Da Certeza. A pesquisa é bibliográfica e refere-se aos textos filosóficos de maneira argumentativa, pretendendo apresentar de forma genérica o pensamento dos principais autores da tradição da filosofia da linguagem e filosofia analítica a respeito das questões propostas, bem como o contexto que envolve o tema, as possíveis soluções anteriores ao principal problema, o ponto de partida do autor e a possível solução do problema aos moldes da linguagem na perspectiva de Wittgenstein.

Palavras-chaves: Termos ficcionais. Filosofia analítica. Epistemologia. Realidade.

ABSTRACT: The present article is entitled: Approaches upon the problem of reference to fictional terms in the perspectives of analytical philosophy and epistemology. The main purpose of the paper consists in analyze how the problem of reference to fictional terms influences the relation between language and reality on the perspective of the analytical Philosophy and epistemology, especially on Wittgenstein's viewpoint based on his work from 1929 and 1930. We intend to characterize on Wittgenstein's philosophy how the traditional epistemic solutions do not fill the gaps that are made regarding the problems of false speech, the reference to fictional terms. The text will be substantiated by the following works from analytical

\footnotetext{
${ }^{1}$ Mestranda em Filosofia pelo Programa de Pós-Graduação em Filosofia da Universidade Federal do Piauí- UFPI. Graduada em Licenciatura Plena em Filosofia pela Universidade Estadual do Piauí - UESPI. E-mail: cattarina8@gmail.com
}

Cadernos Cajuína, V. 4, N. 2, 2019, p.184 - 200.

ISSN: 2448-0916 
Philosophy literature: Frege's Sense and Reference, Russell's On Denoting, and mainly the post Tractatus production of Ludwig Wittgenstein, though it will also support itself in works as Notebooks and the Tractatus-logico-philosophicus itself as a central thread to his most basic thoughts. In his post Tractatus production, the focus will be on On Certainty. The research is bibliographic and refers to philosophical texts in an argumentative way. It intends to present in a generic manner the thought of the main authors in the tradition of language Philosophy and analytical philosophy about the questions proposed, the context around the theme, the previous possible solutions to the main problem, the starting point of the author and the possible solution to the problem of language molds in the perspective of Wittgenstein.

Key-words: Fictional terms. Analytical Philosophy. Epistemology. Reality

\section{INTRODUÇÃO}

O tema proposto neste trabalho é o problema da simetria entre linguagem (ou pensamento) e realidade, da forma como foi explorado pela tradição filosófica desde Frege e Russell com ênfase na solução dada por Wittgenstein. Pretende-se examinar o modo como o filósofo austríaco concebe a solução para o problema de referenciar termos fictícios e enfrentar as questões que giram em torno desse tema.

Tomemos por base fundamental dessa reflexão uma interrogação de um sujeito confuso, suponhamos que um interlocutor chegou em uma sala e disse ter avistado de algo pouco comum, e incrédulo a respeito de sua visão esse sujeito se pergunte se avistara um coelho azul, e por seguinte as pessoas da sala que se questionariam a respeito de tal fato, uns para provar que sim o coelho foi visto e os outros para justificar a crença falsa do sujeito, assim a base seria a questão "Eu vi um coelho azul?"

A questão colocada envolve não somente se foi visto o coelho azul, mas como eu posso ter certeza que o coelho azul não foi visto. A questão envolve o discurso verdadeiro, ilusório, epistêmico e fictício. A arquitetura da resposta para a questão posta começa a partir da forma que se analisa o discurso adotado. A análise será a partir dos argumentos a respeito do modo que se concebe o discurso verdadeiro e falso, como se pode provar ambos sem que os mesmos se anulem.

Grande parte da tradição filosófica debateu por muitos anos se existe o discurso falso, o porquê de se poder nomear o que não existe ou mesmo crer, criar, imaginar o que não existe. A análise começará com autores pioneiros da filosofia da 
linguagem e filosofia analítica: primeiro Frege, em especial seu artigo sobre Sentido e Referência, depois Russell, principalmente o artigo Da denotação, dando foco à solução dada por Wittgenstein com suas principais produções.

É preciso que se tenha certa harmonia e simetria entre o pensamento e a realidade para que se possa julgar que algo exista não somente na mente do sujeito ou que algo seja conhecido apenas por ele. Essa simetria e essa harmonia não são expostas de maneira simples. Se assim o fosse, seria puramente dogmática. A prova que se sabe algo sempre entra em confronto com o desafio epistêmico principalmente do ceticismo, que não deixará de ser abordado. Assim, temos as problemáticas caracterizações mais gerais que definem o que vem a ser a epistemologia, se é possível descrevê-la enquanto a parte da filosofia que se preocupa não com o Ser, mas sim como podemos conhecê-lo e abrangê-lo. Por esta perspectiva, admite-se o Ser previamente para depois duvidar do mesmo e assim, reafirmá-lo e dizer que o conhece e sabe de sua existência.

Neste percurso, cujo tema é sobre o "como se conhece", é colocada a questão epistemológica de como surge o conhecimento. A postura de grande parte da academia filosófica aceita que o conhecimento é o que se pode dizer de uma crença justificada e essa será a postura condutora para elucidar a maior parte das questões que serão também avaliadas segundo o autor chave, bem como em que consiste essa justificação e qual a melhor forma de justificar uma crença. $O$ caminho para se justificar uma crença passa por demandas, tal qual a fixação de um ponto de averiguação para que não haja justificativa cuja referência da proposição seja algo em si mesmo ou caia no retorno infinito, da mesma forma que a natureza da crença apresentada que permeia o discurso.

Wittgenstein tem uma posição bastante particular em relação a essas questões, em especial no seu livro em que ele fala sobre a certeza ${ }^{2}$, no qual comenta a posição de filósofos da tradição analítica e epistêmica tal qual Moore e Russell que discutiram o tema de como se sabe de algo e, desse modo, apresenta sua própria forma de revelar e afirmar o conhecimento de algo com alguma certeza. Wittgenstein constata que uma proposição só pode ser entendida dentro de um jogo de linguagem de um sistema, adotando uma postura de prática e gradação de conhecimentos dentro de um jogo de linguagem que se segue de regras não

\footnotetext{
2 Über gewißheit. Da Certeza.

Cadernos Cajuína, V. 4, N. 2, 2019, p.184 - 200.
}

ISSN: 2448-0916 
explícitas, porém que existem e fazem o papel de fixação do conhecimento. Nosso autor, em sua primeira obra, tenta solucionar o problema do discurso falso, porém ele reformula toda sua escrita nos períodos de 1929 e 1930.

A apuração do tema delimitado nessa pesquisa não diz respeito apenas ao pensamento de Wittgenstein, mas também ao período de sua escrita e produção nos anos 1929 e, predominantemente, a partir da década de 1930, contrapondo também suas respostas as de outros autores. Em suma, tendo como centro este autor, o fio condutor deste artigo será a seguinte questão: em que bases eu posso sustentar um discurso? A menos que alguém duvide do que está sendo dito, o que foi dito será tido como verdadeiro. Mas caso haja dúvida, as bases para que essa mesma dúvida se desfaça começa nas formas de provar que o que foi dito é real, aconteceu e tinha perfeita simetria entre o que se falava e o que de fato acontecia.

\section{A FORÇA DO DISCURSO, SUA VERDADE E A FALTA DELA.}

Nesse primeiro momento, portanto, o que deve ser examinado é a força do discurso, sua verdade e a falta dela. Suponhamos que se queira convencer o leitor que o coelho mencionado no tema de fato foi visto e ele era azul. Imaginemos que o astuto locutor que viu o coelho para afirmar que o tivera visto alegasse que se não acreditarem na existência de seu coelho poderiam estar duvidando da existência de todos os outros, já que as mesmas bases que sustentam o discurso dito ilusório são quase as mesmas que sustentam os que não são.

Quais as bases para o discurso verdadeiro? Esta pergunta, que à primeira vista poderia não parecer difícil, é, na realidade, uma das mais difíceis para se solucionar. Dizer de forma simples o que vem a ser o discurso verdadeiro não condiz com a forma robusta que se deve enfrentar tal problema. Da mesma forma o discurso falso embora possa a princípio ser facilmente comprovado falso, não é de forma alguma uma questão simplista dentro da filosofia.

Existe a capacidade de se falar, pensar e comunicar o discurso falso da mesma forma que se fala, pensa e comunica o verdadeiro. Somos capazes de dizer que um coelho azul foi visto, e se pode falar e discursar sobre tal coelho mesmo não tendo ocorrido tal fato seja de forma estética com a literatura, seja de forma cognitiva, com um engano de uma memória confusa, ou mesmo metafisica com uma ilusão paranoica. 
A princípio, muito mais parece uma questão ontológica, de existência, pois para se provar que não existe o coelho azul tem que se provar que existem coelhos que não são, de forma alguma, azuis e isso teria que se provar colocando tais alegações no mundo, na experiência, pois o discurso é resolvido em vias de empiria.

Porém, a questão é: por que então discursar sobre o que não existe se não existe? E como se consegue fazê-lo? A origem do problema epistêmico tem relação com o problema ontológico. Existe uma necessidade do Ser e essa necessidade do Ser inviabiliza a do não-Ser. Dessa maneira, para existir um discurso verdadeiro é necessário que o discurso falso não exista e o contrário parece válido da mesma maneira.

A existência do discurso falso conduz a um problema difícil, pois as palavras e outros elementos em uma história fictícia, (sem ser em sentido literário), tem os mesmos significados comuns e tem ao mesmo tempo significados distintos, pois a presença da cor azul no discurso do coelho, mesmo estando em uma formulação pouco comum, é entendida, significativa e tem as mesmas regras que se correlacionam, mesmo que o azul nesse contexto não deva ser ativo.

A solução para tal questão ou mesmo a busca dessa solução move o pensamento filosófico a novos caminhos. Ajuda em questões epistêmicas e suas relações com a cognição, aprendizagem, memória. Solucionando o discurso falso a própria questão de como se conhece e também como alguém interpreta o que é dito por outro, podem ser melhores pensadas e resolvidas. E no campo linguístico melhor se revelam tais questões, pois a linguagem é o que melhor figura o mundo segundo nosso autor.

\subsection{DISCURSO FALSO E VERDADEIRO}

Um problema antigo da filosofia é o paradoxo do discurso falso, que para tradição teve sua origem na sofística. Tal paradoxo teve reformulações ao longo dos anos e até chegar a Wittgenstein não perdeu seu teor e complexidade. O paradoxo na visão de Antonio lanni Segatto, em seu livro Wittgenstein e o Problema da Harmonia entre Pensamento e Realidade, tem sua origem remetida a Parmênides, pois seria a conclusão radical de seu discurso sobre o Ser e o não-Ser.

Embora tenha origem na sofística, o paradoxo pode ser entendido como a conclusão da concepção radical de Parmênides acerca da 
relação entre ser, de um lado, e pensamento e discurso, de outro. Como se sabe, Parmênides enuncia no fragmento II de seu poema as duas vias possíveis de investigação: "é, e não é possível que não seja; não é, e é necessário que não seja".

(...)

Quem pensa e diz, pensa e diz o que é. Um discurso, portanto, ou diz algo, diz o que é, sendo necessariamente verdadeiro, ou não diz nada, não tem sentido e não pode sequer ser chamado de discurso. O aparente beco sem saída que resulta daí é conhecido pelo nome de paradoxo do discurso falso: não parece possível que um discurso seja, ao mesmo tempo, falso e significativo (SEGATTO, 2015, p. 20).

Conforme Segatto, (2015), nas passagens por Platão e Aristóteles o paradoxo teve seus primeiros desmontes, primeiro com Platão no Sofista e depois em Aristóteles no Da interpretação. Platão falou sobre a possibilidade do discurso falso por meio da doxa, e Aristóteles formulou a doutrina lógica da proposição tendo como pilar os argumentos platônicos. Não é necessário refazer todos os caminhos até chegar ao nosso autor, o problema chega a ele pelas vias dos filósofos Frege e Russell.

A relação que Frege fazia entre proposição e verdade estava ligada principalmente à sua forma de verificação do valor de verdade e a composição de uma sentença. Frege no seu artigo Sentido e referência defendia que qualquer discurso que não tivesse referência estaria destituído de significado, portanto não traria verdade e realidade à proposição. Compreendendo aí que referência seria o nome que estaria ligado a um objeto no mundo. Essa concepção deixa evidente que textos fictícios carecem de referência, visto que elas não se ligam a objetos e por esse motivo não possuem valor lógico, suas proposições não são autênticas, são destituídas de valor de verdade.

As concepções de Frege a respeito da nomeação e do significado estão relacionadas ao jeito que a proposição se associa com a forma de apresentação de uma entidade, como em seu exemplo "a estrela da manhã" e "a estrela da tarde" que por sua vez tem a mesma estrutura do exemplo de Russell com o "Scott" e "o autor de Waverley" em que os termos podem nomear a mesma coisa e diferir quanto ao significado.

Relativamente aos termos abstratos, cabe o mesmo pensamento como os termos "12" e "o número de países da América do Sul" que nomeiam a mesma coisa, porém diferem em significado, pois observações geográficas tiveram que ser feitas e 
não somente ponderações e um raciocínio apurado para definir que esses dois termos são iguais quanto à nomeação da entidade em questão, isto é, a grandeza numérica abstrata que representa a unidade 12. Essas questões envolvem problemas lógicos mais abrangentes, entretanto tratemos aqui dos termos fictícios.

Em Frege, esse tipo de raciocínio sobre nomeação e significado faz com que sentenças como "Ulisses profundamente adormecido foi desembarcado em Ítaca", ao serem verificadas em seus termos, possuam sentido. Entretanto, carecem de referência, pois em avaliações de relação entre o nome "Ulisses" e possíveis pesquisas sobre sua existência se constataria que essa referência é no mínimo duvidosa. Por esse aspecto, o nome "Ulisses" seria destituído de referência e, portanto, não possuiria valor de verdade.

Para Frege a proposição fictícia não é verdadeira nem falsa, não se pode atribuir referência, não existe um objeto no mundo que referencie a proposição fictícia, por isso não se pode atribuir valor epistemológico. Para este filósofo, a proposição seria um nome, a universalidade e a objetividade seria tal qual o nome próprio. Russell, por sua vez, desenvolveu observações a respeito da teoria fregueana nas quais afirma que as proposições do tipo ficcionais teriam pseudoobjetos como referência.

Russell, assim como Frege, delineou suas proposições sendo iguais em relação a uma entidade, porém essa entidade podendo ter sentidos diferentes. Vimos colocações postas em termos singulares e abstratos, "Scott" e "o autor de "Warvelery", mas esse tipo de avaliação também cabe para termos gerais, para predicados também cabe o mesmo raciocínio e a extensão do termo também tem o mesmo caráter avaliativo. Assim sendo, o termo geral não nomeia uma entidade concreta, porém a verdade desse termo diz respeito a uma entidade, a cada uma das entidades, a todas ou a nenhuma.

Russell no Da denotação admite que uma expressão denotativa é aquela que admite "algum", "qualquer", "cada", "todos", "nenhum" "o atual rei da Inglaterra", "o atual rei da França". Assim suas construções de proposições abrangiam mais termos que Frege poderia abranger, pois termos predicativos também serviriam como expressões denotativas, já que para Russell a existência é um predicado de segunda ordem.

Para Russell, nessa guia, a sentença "o atual rei da França é calvo" seria avaliada em relação ao tipo de objeto que remeteria e o seu desmembramento Cadernos Cajuína, V. 4, N. 2, 2019, p.184 - 200.

ISSN: 2448-0916 
lógico transformaria a sentença em uma conjunção com o quantificador existencial. Mas em conjunções só é verdadeiro quando os dois termos são verdadeiros, ou seja, "o atual rei da França" e "calvo", do contrário poderia assim ser julgado que a frase seria toda falsa. Nessa construção os termos ficcionais podem ser avaliados em uma expressão formal, cuja forma da proposição revelaria sua falsidade e não seu conteúdo.

Russell entendia que existiam objetos lógicos. Sua postura em relação aos objetos era que eles tiram uma ligação direta com a proposição, de forma análoga existiam pseudo-objetos ligados às proposições fictícias e, com esse pensamento, ele tenta superar o problema do terceiro excluído que a solução fregeana não englobava. Assim, as sentenças como "o rei da França é calvo" poderiam ser analisadas e constatadas com o valor de verdade, e com análises corretas se constataria o valor falso.

\section{WITTGENSTEIN E SUAS PRODUÇÕES TARDIAS PARA SOLUÇÃO DA QUESTÃO}

O problema de Frege e Russell era o mesmo dos filósofos gregos e tanto Frege quanto Russell em suas teorias deram prioridade ao discurso verdadeiro, como se na linguagem, em algum momento, sendo ela formalizada o suficiente, ocorresse de forma lógica o reconhecimento da verdade no discurso e esse se bastaria.

Wittgenstein revê as questões sobre o "nome próprio" em G. Frege e o "objeto" para B. Russell, em ambos os autores a proposição pode ter relação direta com o objeto e a palavra em si conter a relação bipolar verdadeiro/falso que traziam complicações para a dissolução do paradoxo, segundo nosso autor.

Para entender o posicionamento de Wittgenstein em relação ao paradoxo do discurso falso é preciso compreender como 0 autor entende a relação significado e palavra e o que o mesmo pensa a respeito das proposições, posto que sua posição com relação a questão difere de Frege e Russell principalmente na descrição da proposição e sua relação com o mundo.

Suas primeiras formulações para pensar o discurso falso começam já nos Cadernos em que nosso autor questiona: "Em " $p$ " pode ser reconhecido nem mais nem menos do que em " $p$ ". Como uma situação pode concordar com " $p$ " e não 
concordar com " p"?" (WITTGENSTEIN, 1961, p. 37e). Wittgenstein, nos mesmos textos, também se perguntou como era possível uma figuração fazer representação do que não existe? Essa pergunta levou nosso autor a formular uma teoria em que era possível preservar o discurso verdadeiro e ainda assim conseguir deixá-lo em conformidade com o falso sem que ambos se anulassem.

$\mathrm{Na}$ visão de nosso autor, a proposição precisa projetar o mundo. Para entender a proposição em Wittgenstein é necessário recobrar a velha separação entre fundo essencial e superfície aparente e entender a diferença entre o que é o sinal e o símbolo, o aprendizado sensível e o material. Da mesma forma, para que a proposição projete o mundo ela tem que manter uma relação de afiguração com ele.

3.11 Utilizamos o signo sensível e perceptível (signo sonoro ou escrito, etc.) da proposição como projeção da situação possível.

O método de projeção é o pensar do sentido da proposição.

3.12 Chamo signo proposicional o signo pelo qual exprimimos o pensamento. E a proposição é o signo proposicional em sua em sua relação projetiva com o mundo.

3.13 A proposição pertence tudo que pertence à projeção, não, porém, o que é projetado.

Portanto, a possibilidade do que é projetado, não, porém, o que é projetado, não, porém, este último.

A proposição, portanto, não contém seu sentido, mas a possibilidade de exprimi-lo.

("O conteúdo da proposição" quer dizer o conteúdo da proposição significativa.)

Está contida na proposição a forma de seu sentido, não, porém, seu conteúdo.

3.14 O signo proposicional consiste em seus elementos, as palavras, estão relacionados uns aos outros de maneira determinada.

(WITTGENSTEIN, p. 62, 1968)

Portanto, em Wittgenstein, é possível afirmar que: o mundo é projetado de maneira experimental pelo signo proposicional; na proposição se deve ver a bipolaridade do verdadeiro e do falso de maneira articulada; a figuração é a proposição; e, a compreensão da verdade e falsidade efetivas deixam em evidência o princípio da independência do sentido e a bipolaridade da proposição.

No Livro azul e até antes dele Wittgenstein já dizia que o substantivo faz com que procuremos o objeto que corresponda a ele, isso gera uma das maiores perturbações filosóficas: buscar sempre uma referência a todos os nomes significativos. Dessa forma as definições ostensivas devem atribuir um significado à 
palavra.

Ao se procurar para cada substantivo um objeto no mundo, deixa-se de fora muitas palavras que não encontram sua ostensão como "este", "não", "que" etc. Wittgenstein dá o exemplo da palavra "tove" e comenta o quão dificultoso é para quem deseja explicar palavras usando suas extensões e não deixar em suspenso alguma pequena palavra. Segatto resume o que o nosso autor pensa em relação ao pensamento sobre o nome e objeto:

Assim como seus predecessores gregos, Wittgenstein entende que, para um nome, significar é simbolizar algo; para uma proposição, ao contrário, significar é escolher um dos polos de uma alternativa exclusiva. Com isso, coloca-se uma diferença entre nomear e descrever: um nome nomeia algo na realidade; uma proposição descreve uma concatenação possível de objetos simbolizados por nomes (SEGATTO, 2015, p. 25).

O que fica claro é que cada palavra não contém um sentido verdadeiro e falso e seu significado não está presente, é preciso uma articulação para que se pense sobre a concordância com a realidade ou o contrário, assim como ocorre com a proposição, na qual é a articulação dos nomes que torna a proposição verdadeira, e é a substituição dos objetos dessa articulação que enfatiza a correspondência entre o falso e o verdadeiro.

Das formulações mais recorrentes em textos sobre linguagem, o discurso falso vem como forma de discurso fictício, aquele cujo teor é relacionado não a um objeto no mundo, mas, pelo contrário, não se relaciona a nenhum objeto. Como o é na maior parte dos casos em literatura e textos ditos não científicos. Para alguns filósofos, assim como para Platão, o discurso fictício é mentiroso.

Existem certos textos fictícios em que o autor não se prende apenas a estórias "inventadas", gêneros textuais e tipos de escritas cujo discurso embora seja fictício pode revelar algo de verdadeiro, ou mesmo filosófico como em autores como Sartre, por exemplo. As observações feitas em relação ao tema deste trabalho se relaciona principalmente aos textos fictícios que não são ligados a literatura.

John Searle analisou o discurso ficcional separando-o da literatura; com base em seu texto $\mathbf{O}$ estatuto lógico do discurso ficcional se pode separar o discurso literal do discurso sério, ou o que ele chamou de locuções literais e locuções sérias que são independentes das locuções figurativas e literais de acordo com sua teoria dos atos de fala ou atos ilocutórios. Seguindo o mesmo raciocínio do autor o 
trabalho vai se valer das locuções sérias a serem analisadas e não da ficção literária. Searle observou que existem regras para os elementos tanto fictícios quanto não fictícios.

Seu trabalho nesse texto é explicar o porquê de a ficção não se tratar de mentiras. O discurso sério para Searle é aquele cujo compromisso de quem escreve é o relato real do que ocorre, já na ficção não séria o autor não se compromete com o que realmente ocorre. Se tratarmos a frase "eu vi um coelho azul" como fictícia teríamos uma definição completamente diferente da que podemos dar se tratarmos como um relato de alguém que quer dizer que viu tal coelho.

Parece-me útil pensar que estas são regras que correlacionam palavras (ou frases) com o mundo. Pensemos nelas como regras verticais que estabelecem conexões entre a linguagem e a realidade. Ora, o que torna possível a ficção, segundo sugiro, é um conjunto de convenções extralinguísticas, não semânticas, que rompem a ligação entre as palavras e o mundo estabelecida pelas regras atrás mencionadas. Pensemos nas convenções do discurso ficcional como um conjunto de convenções horizontais que rompem as ligações estabelecidas pelas regras verticais. Suspendem as exigências normais estabelecidas por estas regras. Tais convenções horizontais não são regras de significado; não fazem parte da competência semântica do falante. Consequentemente, não alteram ou modificam os significados das palavras ou outros elementos da língua (SEARLE, 2011, p. 34).

Searle argumenta que as convenções extralinguísticas são as responsáveis por conseguirmos estabelecer regras não semânticas que podem romper essa relação com o mundo sem tirar o seu significado. Sua interpretação do discurso ficcional serve para pensar em como pode ser analisado um discurso falso sem leválo apenas como mentiroso ou falacioso. Suas regras são diferentes. Contudo, suas regras ficam claras em relação ao perfil de texto ficcional dito por Searle, mas, e quando se trata de um relato que é por engano e não por formulação fictício? As mesmas regras podem ser aplicadas?

A relação de Wittgenstein com a regra é posta em destaque, principalmente no seu texto Investigações filosóficas (1953). Para nosso autor, a regra é como um trilho invisível. A noção de regra e sua aplicação é uma das bases fundamentais para se entender os jogos de linguagem e seu funcionamento. $O$ que nosso autor mais demonstra em sua escrita é como a regra apesar de não ser explícita é evidente e é seguida. Com isso, o erro na aplicação de uma regra é indeterminado porque também é indeterminado como se aprende uma regra. 
Wittgenstein volta sua produção pós-Tractatus à questões práticas. Com essa posição ele difere dos autores anteriores e a visão de um sistema linguístico esclarece melhor questões que tanto Frege quando Russell não revelaram sobre o objeto e sua relação com a proposição, a ontologia do estado de coisas que Wittgenstein adota é de fundamental importância para se formar uma proposição independente do mundo e defender a lógica como principal garantia de verdade.

Após as suas revelações sobre a independência da lógica em relação a questões epistêmicas, que em si já resolviam problemas antes quase insolúveis, seus pontos de vista são revistos pelo próprio autor e ele acrescenta o uso e a prática para mover melhores vias de soluções para problemas que envolvam 0 pensar e a realidade.

152. Não aprendo explicitamente as proposições que são assente pra mim. Descubro-as subsequentemente como o eixo em torno do qual roda um corpo. Esse eixo não está fixo no sentido de haver alguma coisa a segura-lo, mas o movimento em torno dele determina a sua imobilidade.

153. Nunca ninguém me ensinou que as minhas mãos não desaparecem quando não estou a olhar para elas. Nem se pode dizer que eu parto desse pressuposto da verdade dessa proposição nas minhas afirmações, etc., (como se elas repousassem sobre isso), enquanto ela apenas tem sentido a partir do resto do nosso processo de produzir afirmações.

156. A fim de fazer um erro, um homem já tem de julgar de acordo com a humanidade.

159. Em criança aprendemos fatos; por exemplo, que todos os seres os seres humanos possuem um cérebro, e acreditamos neles. Acredito que existe uma ilha, a Austrália, com determinada forma, etc., etc.,; acredito que tive bisavós, que as pessoas que se declararam meus pais eram realmente os meus pais, etc. Essa crença pode não ter sido nunca expressa; mesmo o pensamento de que era assim pode nunca ter sido pensado.

161. Aprendi uma enorme quantidade de coisas e aceitei-as na base da autoridade de homens; depois achei que algumas dessas coisas se confirmavam e outras não, de acordo com a minha própria experiência. (WITTGENSTEIN, 1969, p. 57).

É em uso que se determina sentidos e significados, é na prática que se joga, é somente no uso da regra e com a prática da mesma que se consegue ver um erro, ou uma não correspondência com a verdade. É a aplicação da regra que diz sua relação com o falso e o verdadeiro, portanto, com a realidade.

Com essa postura de prática e aplicação, não é a regra aprendida que deve 
ser revisada, mas sim deve ser revisado como se aprende a regra. Disso resulta que ao aprender a calcular aprendemos a natureza do cálculo. Com isso não é necessário a regra e sim ter feito o cálculo de acordo com uma regra, e isso basta. $A$ maneira como autores, principalmente Kripke, interpretam esse pensamento será avaliada, pois a introdução do paradoxo cético que Kripke aponta em Wittgenstein se faz necessário para mensurar a complexidade da regra nesses autores.

194. Com a palavra <<certa>> exprimimos convicção completa, ausência de qualquer dúvida e a partir daí tentamos convencer as outras pessoas. É certeza subjetiva.

Quando é que qualquer coisa é objetivamente certa? Quando não é possível um erro. Mas que espécie de possibilidade é essa? Não deve o erro ser logicamente excluído?

196. Evidência segura é a que aceitamos como segura, é a que nos orienta quando agimos com segurança sem qualquer dúvida.

O que chamamos <<erro>> desempenha um papel muito especial nos nossos jogos de linguagem, e o mesmo acontece com o que consideramos como evidência segura.

200. Realmente << a proposição é ou verdadeira ou falsa >> só significa que tem de ser possível a favor ou contra ela, mas não dizer qual o fundamento para essa decisão. (WITTGENSTEIN, 1969, p. $65)$.

A regra é que torna viável o jogo linguístico, pois, embora exista certa discussão sobre como a regra é seguida e se a mesma é seguida de forma correta, mesmo assim é a regra que define o jogo. Pois a prática e o uso são os principais fatores para a construção tanto da regra quanto dos jogos de linguagem, isso por si define o que e o como se conhece um determinado ponto verdadeiro ou falso dentro de um jogo linguístico. Existe um sistema que deixa claro quais as práticas e como se monta um quadro de referência de sistema.

95. As proposições que descrevem essa imagem do mundo poderiam pertencer a uma espécie de mitologia. E o seu papel é semelhante aos das regras de um jogo. E o jogo pode ser aprendido puramente pela prática, sem aprender quaisquer regras explicitas.

139. São necessárias, para estabelecer uma prática regra, não só regras, mas também exemplos. As nossas regras têm lacunas e a prática tem de falar por si mesmo (WITTGENSTEIN, p. 41- 53, 1969).

Antes de tudo, uma regra não é uma coisa que deve ser aprendida e logo depois aplicada em circunstâncias particulares, pois uma regra não se constrói de forma independente dos seus eventos próprios de aplicação. De forma análoga, 
poderíamos fazer um paralelo entre as imagens de discurso falso ou verdadeiro que se constroem com a prática no uso e no agir dessas imagens.

\section{CONCLUSÃO}

As produções pós-Tractatus são as que mais se destacam em relação a posturas que envolvam conhecimento, regra e outras questões que possam envolver a questão do paradoxo do discurso falso e sobre questões que envolvam o discurso ilusório, fictício. São as produções dos anos 1929 e 1930 o foco para a solução da questão posta no tema sobre como revelar se o discurso ilusório se define dessa forma por si, como deve ocorrer com o discurso verdadeiro.

Resumidamente nessas produções pós-Tractatus nosso autor argumenta que o fator social (prática) pode resolver o problema da harmonia entre a linguagem e a realidade. Sua postura sobre a regra e sobre o sistema linguístico revela o modo que o autor interpreta de que maneira se pode aprender e resolver questões dentro do jogo de linguagem. A introdução do quadro de referência, que é montado de forma tão prática quanto os jogos, dá margem para interpretações de como um conhecimento externo se liga a conhecimentos de um sujeito que é construído desde criança.

É visão de como é o erro e o acerto, nessa perspectiva da aplicação da regra, que revela de forma mais clara o que corresponde com 0 real e o que não corresponde. O sujeito não avalia somente por si, ele coloca o erro e o acerto em contextos e com isso têm melhores bases para afirmar seu discurso.

Existe nessa postura a preservação do discurso falso sem que o mesmo prejudique o entendimento do que vem a ser o verdadeiro. Ao contrário dos outros autores que colocavam um em detrimento do outro, Wittgenstein procura harmonizar os dois discursos sem que precise haver a anulação das verdades de ambos, respeitando as regras tanto analíticas quanto epistêmicas que envolvem a questão.

Wittgenstein não coloca o sujeito de maneira singular, no sentido que o só sujeito afirma seu conhecimento em que ele concorda ou não concorda com a realidade. A postura de Wittgenstein é que o sujeito não tem em si essa bipolaridade do discurso, mas ele molda suas posições de acordo com o contexto e suas experiências. É o substituir das relações que o sujeito faz com os objetos no mundo, a sua relação com suas visões anteriores e a relação que outros tiveram sobre uma 
mesma questão que faz o sujeito reler o que está sendo aplicado e confirmar sua postura de concordar ou não se viu um coelho azul.

Em suma, a posição de Wittgenstein sobre a relação linguagem e mundo oferece uma perspectiva mais interessante para tratar do problema da referência e conhecimento de entidades ficcionais por seu olhar de que a palavra não se liga ao objeto, que ambos estão em relação ao sistema que se encontram. Essa postura garante proposições cujo teor de seu significado está na prática e não somente na forma. A sua posição de que existe gradação de certeza e dúvida e sua perspectiva do quadro de referência alicerçam desde as crenças mais básicas às mais complexas de um sujeito. Com isso, tanto termos ficcionais quanto termos não ficcionais têm suas referências bem colocadas em quadros e sistemas podendo assim se construir regras para regência dos dois tipos de termos sem que ambos possam se anular.

\section{REFERÊNCIAS}

FREGE, Gottlob. Lógica e Filosofia da Linguagem. Tradução, introdução e notas de Paulo Alconforado. 2. ed. São Paulo: Edusp, 2009.

GURGEL, Diogo de França. Metáforas em imagens de mundo. CONIGLIO, Marcelo. et al. (Orgs.). Filosofia da linguagem e da lógica. São Paulo: ANPOF, 2017. p. 119-137. (Coleção XVII Encontro ANPOF).

MARTINS, Alex Lara. Metaficção e ceticismo: uma análise da abordagem analítica ao problema do discurso ficcional. In: CARVALHO, Marcelo; FIGUEIREDO, Vinícius. (Orgs.). Filosofia Contemporânea: lógica, linguagem e ciência. São Paulo: ANPOF, 2013. p. 43-57.

MELO, Ederson Safra. O Paradoxo do Mentiroso e Lacunas de Valores de Verdade. In: CARVALHO, Marcelo; BRAIDA, Celso; SALLES, João Carlos; CONIGLIO, Marcelo Estevan. (Orgs.). Filosofia da Linguagem e da Lógica. São Paulo: ANPOF, 2015. p. 384-402.

MOORE, George Edward. Escritos Filosóficos. Tradução Paulo R. Mariconda. São Paulo: Nova Cultural, 1989.

ROLLA, Giovanni. Limites epistêmicos: conhecimento e angústia intelectual. In: CARVALHO, Marcelo; FIGUEIREDO, Vinícius. (Orgs.). Filosofia Contemporânea: lógica, linguagem e ciência. São Paulo: ANPOF, 2013. p. 345-354.

SALIS, Fiora. Entidades Ficcionais. In: BRANQUINHO, João; SANTOS, Ricardo. Compêndio em Linha de Problemas de Filosofia Analítica, Centro de Filosofia da Universidade de Lisboa: Lisboa, 2013. p. 1-38. Disponível em: 
$<$ http://repositorio.ul.pt/handle/10451/10860>. Acesso em: 27 ago. 2018.

SANTOS, Vinícius de Faria dos. O Contextualismo de Wittgenstein envolve um Ceticismo Semântico? In: CARVALHO, Marcelo; BRAIDA, Celso; SALLES, João Carlos; CONIGLIO, Marcelo Estevan. (Orgs.). Filosofia da Linguagem e da Lógica. São Paulo: ANPOF, 2015. p. 149-159.

SEARLE, John R..Wittgenstein and the Background. American Philosophical Quarterly, Champaign, v. 48, n. 2, abril, 2011, p. 119-128. Disponível em: <http://www.jstor.org/stable/23025082> Acesso em: 16 ago. 2018.

. O estatuto lógico do discurso ficcional. Disponível em:<https://criticanarede.com/logicaficcional.html >Acessado em: 04/08/2018.

SEGATTO, Antonio lanni. Wittgenstein e o problema da harmonia entre pensamento e realidade. São Paulo: Editora Unesp digital, 2015.

. Wittgenstein e a prática de seguir regras. In:

CARVALHO, Marcelo; BRAIDA, Celso; SALLES, João Carlos; CONIGLIO, Marcelo Estevan. (Orgs.). Filosofia da Linguagem e da Lógica. São Paulo: ANPOF, 2015. p. $160-173$.

SILVA, Jeane Vanessa Santos. Há base linguística para o contextualismo epistemológico? CONIGLIO, Marcelo. et al. (Orgs.). Filosofia da linguagem e da lógica. São Paulo: ANPOF, 2017. p. 77-96. (Coleção XVII Encontro ANPOF).

KRIPKE, Saul. On rules and private linguage. In. The nature of linguage. Cambridge: Harvard University Press, 1982.

RUSSELL, Bertrand. Da Denotação. In: Os Pensadores. Tradução de: Pablo Rubén Mariconda. São Paulo: Abril Cultural, 1973.

Florianópolis: Editora Herder, 2005.

Os Problemas da Filosofia. Tradução de Jaimir Conte. Principles of Mathematics. Cambridge: Cambridge

University Press.

WITTGENSTEIN, Ludwig. Algumas observações sobre a forma lógica. Tradução de Eduardo Coutinho Lourenço de Lima. Contextura, Belo Horizonte, v.1, n. 1, 2004, p. 58-61.

1961. $131 \mathrm{p}$.

Notebooks 1914-1916. New York: Harper \& Brothers,

. Observações Filosóficas. Tradução Adail Sobral e

Maria Stela Gonçalves. São Paulo: Edições Loyola, 2005.

. Da certeza. Tradução Maria Elisa Costa. Lisboa:

Edições 70, 1969.

Cadernos Cajuína, V. 4, N. 2, 2019, p.184 - 200.

ISSN: 2448-0916 
. O livro castanho. Tradução Jorge Marques. Edições

$70,1992$.

$70,1992$.

. O Livro Azul. Tradução Jorge Mendes. Lisboa: Edições

Investigações Filosóficas. In: Os pensadores.

Tradução de: José Carlos Bruni. São Paulo: Abril Cultural, 1975.

Tractatus logico-philosophicus. Tradução e

apresentação de José Arthur Giannotti. São Paulo: Editora Nacional, 1968. 